\title{
A escuta qualificada na assistência social: Da postura diagnóstica às formas (po)éticas de escutar
}

\section{Qualified listening in the social assistance: From a diagnostic position to the (po)ethical listening forms}

\section{Escucha calificada en asistencia social: De la posición de diagnóstico a las formas éticas (po) de escuchar}

\author{
Natália Sanches* \\ Universidade Estadual de Londrina - UEL, Londrina, Paraná, Brasil \\ Rafael Bianchi Silva** \\ Universidade Estadual de Londrina - UEL, Londrina, Paraná, Brasil
}

\begin{abstract}
RESUMO
O presente artigo tece considerações acerca da terminologia "escuta qualificada" no contexto do Sistema Único de Assistência Social (SUAS). Com o objetivo de ampliar a instrumentalização e intervenção da Psicologia na proteção social, foi feita uma pesquisa documental e bibliográfica acerca do conceito de escuta, como ela se articula nas produções acadêmicas na área da Assistência Social e nos materiais parametrizadores da política. Foi possível identificar a presença de uma escuta diagnóstica nos parâmetros do trabalho social que entendemos encontrar-se fortemente articulada com o conceito de "exame" de Foucault (1999). Por outro lado, em diálogo com Mèlich (2001) e Larrosa (2014), consideramos outras maneiras de realizar o processo de escuta das populações atendidas na referida política pública, subvertendo a lógica de vigilância-punição.
\end{abstract}

Palavras-chaves: Psicologia, Assistência Social, Escuta.

\section{ABSTRACT}

This article discusses the term "qualified listening" in the context of the Sistema Único de Assistência Social (SUAS). In order to broaden the instrumentalization and intervention of Psychology in social protection, a documental and bibliographic research about the concept of listening was made, as it was articulated to the academic productions in the area of Social Work and in the parameterizing materials of public politics. It was possible to identify the presence of a diagnostic listening in the parameters of social work, which we believe that is strongly articulated with the concept of "examination" by Foucault (1999). On the other hand, in dialogue with Mèlich (2001) and Larrosa (2014), we considered other ways to perform the process of listening to the populations served in the referred public policy, subverting the logic of surveillance-punishment.

Keywords: Psychology, Social Assistance, Listening. 


\begin{abstract}
RESUMEN
Este artículo aborda el término "escucha calificada" en el contexto del Sistema Unificado de Asistencia Social (SUAS). Con el fin de ampliar la instrumentalización e intervención de la psicología en la protección social, se realizó una investigación documental y bibliográfica sobre el concepto de escucha, tal como se articula en las producciones académicas en el área de asistencia social y en los materiales de parametrización de la política. Fue posible identificar la presencia de la audición diagnóstica en los parámetros del trabajo social que creemos estar fuertemente articulados con el concepto de "examen" de Foucault (1999). Por otro lado, en diálogo con Mèlich (2001) y Larrosa (2014), consideramos otras formas de llevar a cabo el proceso de escuchar a las poblaciones atendidas en la política pública referida, subvirtiendo la lógica de la vigilancia-castigo.
\end{abstract}

Palabras-clave: Psicologia, Asistencia Social, Escucha.

O campo da Assistência Social já não pode ser considerado como um espaço de atuação recente para os psicólogos, visto que há décadas, antes mesmo da sua configuração como política pública, os profissionais têm desenvolvido saberes e práticas nesse contexto (Cordeiro, 2018). Contudo, a partir da implementação da Política Nacional de Assistência Social (PNAS) e da Norma Operacional Básica de Recursos Humanos do Sistema Único de Assistência Social (NOBRH/SUAS) (Brasil, 2012a), as práticas desenvolvidas pelos técnicos atuantes na política devem estar alinhadas às prescrições presentes nos diversos cadernos que passaram a ser produzidos continuamente a partir do início da primeira década dos anos 2000.

Da mesma maneira, são impulsionadas tanto a produção acadêmica que se propõe a problematizar a atuação da Psicologia na política como também a materialização de normas técnicas provenientes dos conselhos federal e estaduais regulamentadores da profissão. Nesse sentido, atualmente existe um arcabouço de materiais que servem de ponto de partida para o desenvolvimento das práticas do psicólogo nesse contexto.

Somada a tais pontos, a realização de uma série de experiências com grupos de formação com técnicos atuantes na política nos colocou envoltos em um universo simbólico constituído por palavras e expressões que concerniam especialmente ao que se (des)entende pelo trabalho do psicólogo na Assistência Social, provocando discussões acerca dos sentidos do trabalho e das as práticas que se efetivam no cotidiano dos serviços.

Esse artigo visa trazer considerações sobre a terminologia "escuta". Isso porque, além da constatação de que a escuta costuma ser atribuída enquanto função do profissional da Psicologia no cotidiano dos serviços, os próprios cadernos da política desenvolvem a noção articulada à subjetividade, histórias e narrativas. Nesse sentido, a escuta qualificada assume importante papel entre as intervenções a serem implementadas pelo trabalho social com o objetivo de 
favorecer, em última instância, a capacidade transformativa das famílias perante a realidade social.

A terminologia "escuta" aparece nos documentos como uma prática não restritiva aos psicólogos, mas especialmente alinhada à formação dessa categoria profissional. Na medida em que restringe ações de caráter terapêutico compreendidas como "práticas psicoterapêuticas, psicodiagnósticas e psicopedagógicas" (Brasil, 2012b, p. 16), considera que a Psicologia operar-se-á, no âmbito do SUAS, através da escuta dos aspectos subjetivos envolvidos nas situações de vulnerabilidade às quais as populações e territórios encontram-se submetidos.

Alguns dos cadernos da política (Brasil, 2005; 2012a; 2012b; 2016) nos trazem considerações acerca de uma escuta qualificada, de caráter essencialmente diagnóstico, seja ela voltada para a realidade dos indivíduos e suas famílias, seja para a dimensão territorial. Porém, a trajetória da pesquisa articulada às vivências dos grupos com profissionais denuncia outras maneiras de se escutar que transcendem uma escuta diagnóstica, considerando que essa modalidade enquadra as vidas de determinadas populações às terminologias cunhadas pela ciência.

Alguns questionamentos se interpõem: o que o profissional inserido na Assistência Social escuta? Gosto de pensar que dentro desse campo escuta-se a vida como ela é. A vida que não é passível de ser recortada. Dentre os profissionais com os quais me deparei em minha trajetória de formação, uma me marcou por ser o tipo de pessoa que pareceu sempre ter algo novo a dizer dentro do campo da Assistência Social (que algumas vezes se configura, em minha percepção, enquanto reprodutora de determinados discursos e espaço de repetições). Essa profissional afirmou que o objeto da política era justamente o não-objeto, sendo sobre aquilo que falta e continuará faltando que a política opera, ou seja, na falha de outras políticas, do Estado, do aparato jurídico, educacional; nas falhas dos dispositivos de saúde, da mobilidade urbana, das políticas de habitação, de alimentação e todas as políticas que foram construídas para vir a dar conta do que nunca entrará na conta por completo: a vida.

Dessa maneira, o que se apresenta ao técnico atuante nos diferentes equipamentos do SUAS são narrativas complexas e múltiplas, não capturáveis pelos discursos acadêmicos (representados pelos técnicos) nem pela própria discursividade da política (presentes nos documentos que a materializam).

Hüning, Cabral e Ribeiro (2018) ao descreverem uma experiência de estágio na Assistência Social em um território marginalizado da cidade de Maceió, relatam a constante insuficiência teórica, técnica e operativa da Psicologia enquanto ciência na medida em que adentra territórios e histórias antes não conhecidos nem narradas. As autoras irão situar historicamente os saberes psicológicos enquanto 
produtores de "verdades" sobre o outro em uma relação colonialista, distanciada e à margem do "mundo real". Com ênfase nas "narrativas", as autoras denominam-se a partir o trabalho realizado como:

... catadoras, que buscam nos restos e escombros do progresso elementos para contar outras histórias, permitindo 0 aparecimento daquela(e)s que foram subjugada(o)s pelas narrativas históricas ou científicas oficiais. [...]. Trazemos para - campo discursivo acadêmico aquilo que no cotidiano da cidade, da produção de conhecimento e como alvo da política de assistência social costuma-se apresentar-se como o desvio, o inadequado, o resto, a partir das afetações que provocam em nós - também sujeitos de uma experiência de encontro com vidas infames e territórios marginais (Hüning et al., 2018, p. 57).

Aquilo que "falta", mencionado na fala da profissional descrita anteriormente, refere-se aos ordenamentos presentes em um sistema de necessidades humanas dos quais as populações usuárias da Assistência Social historicamente estiveram à margem. Como afirmam Hüning et al. (2018, p. 54), trata-se de "Um mundo sem saneamento e sem as condições básicas de vida para a maioria de 'nós'. Mas 'nós' não o habitamos! Raramente tomamos conhecimento de sua existência". Nesse sentido, os profissionais operantes na política tendem a se orientar-se através de uma proposta éticopolítica na qual a "falta" seja passível de ser tamponada, seja pela cessão de benefícios emergenciais específicos, seja pelo saber técnico-profissional pautado muitas vezes por práticas prescritivas e higienizadoras.

Tendo a "falta" como balizadora das práticas, a Assistência Social perderia o caráter de prevenção na qual materializa, inclusive, um de seus níveis de proteção social - a básica. Isso colocado, o que efetivamente teria mudado desde a implantação do SUAS enquanto uma política pública que objetiva também romper com práticas assistencialistas anteriores (caracterizadas pela orientação do que "falta", através de ações pontuais, não acompanhadas sistematicamente e tampouco avaliadas)?

Embora não seja o objetivo desse trabalho discorrer especificamente sobre os rompimentos e continuidades das práticas assistencialistas que disputam o campo da Assistência Social ainda na atualidade, fazse necessário considerar que a construção de parâmetros a partir dos quais tantos as instituições quanto os profissionais devem orientar suas práticas dá início à profissionalização dessa política, e que só efetivar-se-á cotidianamente nos espaços coletivos de construção e reflexão sobre o trabalho. 
O objetivo desse trabalho é traçar algumas considerações acerca da escuta no âmbito do SUAS, em especial a partir dos desafios colocados pela atuação na proteção social básica. Para tanto, é realizado um diálogo com o conceito de exame - proposto por Foucault (1987) - bem como com as implicações ético-políticas presentes no trabalho do técnico inserido nesse contexto.

Enquanto categorias de análise, além da escuta diagnóstica, diretamente associada à vigilância social, também é possível conceber na atuação do psicólogo práticas de resistência que permeiam a própria escuta, que também foram descritas por profissionais atuantes na política na participação em grupos de formação. É nesta escuta que resiste aos saberes científicos que articulamos a concepção de linguagem (po)ética de Mèlich (2001) e Larrosa (2014) como uma possível contribuição para realização de um trabalho que não tenha como único horizonte possível a vigilância e normalização dos corpos.

\section{Escutar, traduzir e identificar enquanto práticas de enquadramento}

O rio que fazia uma volta atrás de nossa casa era a imagem de um vidro mole que fazia uma volta atrás de casa. Passou um homem depois e disse: Essa volta que o rio faz por trás de sua casa se chama enseada. Não era mais a imagem de uma cobra de vidro que fazia uma volta atrás de casa. Era uma enseada. Acho que o nome empobreceu a imagem (Barros, 2016, p. 20).

Afinal, o que são as práticas na Política Nacional de Assistência Social senão um conjunto de sentidos compartilhados entre técnicos, usuários e não usuários da política? Os cadernos, normativas e diretrizes elaborados entre os anos de 2004 a 2016 pelo Ministério de Desenvolvimento Social, assim como as notas técnicas emitidas pelos Conselhos Federal (CFP) e Estaduais (CRPs) de Psicologia e Serviço Social (CFESS) têm entre seus objetivos a delimitação desse campo a partir de discursos que fundamentam práticas que, na materialidade cotidiana da política, não se esgotam nas normativas e notas técnicas. Entretanto, enquanto universo simbólico que se materializa em instituições disciplinares, a linguagem que se forma e se transversaliza nesses lugares são dispositivos de poder onde é exercida incisivamente a vigilância social.

No segundo volume de "Orientações Técnicas sobre o PAIF" (Brasil, 2012b), a escuta é localizada principalmente no processo de "Acolhida", que consiste no primeiro contato qualificado do usuário com a política de Assistência Social. É possível identificar o caráter diagnóstico dessa escuta que deve apreender dados do campo 
relacional familiar, compreender os múltiplos significados das demandas e vulnerabilidades, identificar recursos e potencialidades e como esses múltiplos atravessamentos relacionam-se com o território em que se encontram.

Segundo os documentos da política, a escuta profissional deve permear esse campo simbólico: relações familiares, demandas e vulnerabilidades, recursos e potencialidades e relações com 0 território. Seguindo a mesma direção de trabalho, o caderno "Fundamentos ético-políticos e rumos teórico-metodológicos para o fortalecimento do Trabalho Social com Famílias na Política Nacional de Assistência Social" (Brasil, 2016), há três perguntas fundamentais que devem orientar o processo de construção de conhecimento junto às famílias. Essas três perguntas relacionam-se intimamente com 0 exercício da vigilância social e pode caracterizar-se como o que Foucault descreve por exame:

O exame combina as técnicas da hierarquia que vigia e as da sanção que normaliza. É um controle normalizante, uma vigilância que permite qualificar, classificar e punir. Estabelece sobre os indivíduos uma visibilidade através da qual são diferenciados e sancionados [...] Nessa técnica delicada estão comprometidas todo um campo de saber, todo um tipo de poder [...] Mas sua própria tecnologia, esse pequeno esquema operatório que tem tal difusão (da psi/quiatria a pedagogia, do diagnóstico de doenças a contratação de mão de obra), esse processo tão familiar do exame, não põe em funcionamento, dentro de um só mecanismo, relações de poder que permitem obter e constituir saber? (Foucault, 1987, p. 153).

Enquanto tecnologia de controle, as práticas assistenciais contemporâneas visam "regular o cotidiano, sobrecodificando e descodificando os acontecimentos e gerindo os modos de vida pela utilização cada vez maior dos processos de normalização e dos discursos da segurança" (Gama, 2017, p. 57). Nessa direção há um aparato técnico, instrumental e burocrático materializado no Cadastro Único, condicionalidades dos programas Bolsa Família, BPC (Benefício da Prestação Continuada) e nos diferentes tipos de relatórios construídos pelos técnicos, entre outros, que corroboram com 0 controle e normalização da vida.

Especificamente nesse contexto, Caliman e Tavares (2013) descrevem como, na contemporaneidade, o dispositivo "risco social" atualiza os mecanismos disciplinares e reguladores dos corpos à medida em que os relacionam diretamente com os sujeitos construídos como naturalmente perigosos. Segundo as autoras: 
A análise do risco social como dispositivo de controle volta-se para a perspectiva do gerenciamento do risco que se dá nas políticas não em relação aos fatores (ambientais, econômicos, situacionais, etc.) de insegurança ou de perigo, presentes na vida das crianças ou de suas famílias, mas em relação aos sujeitos, às pessoas que, no plano do direito, estariam em risco. O jovem é visto como o risco, aquilo que precisa ser gerenciado, controlado, governado. A família é definida como o risco, e não mais como estando em risco (Caliman \& Tavares, 2013, p. 941, grifo nosso).

Nesse sentido, há uma contradição sine qua non no campo da Assistência Social: à medida em que, nos documentos, encontra-se certo cuidado com a linguagem no que tange a não culpabilização das famílias acerca de sua condição de vulnerabilidade/risco social, é no seio da família que irão se operar os saberes técnicos que favorecem a superação de tal condição. Se as famílias não são as responsáveis pela condição de vulnerabilidade que as atravessam, então por que o saber técnico toma a família enquanto objeto de suas intervenções? O que se apresenta, em última instância, é o governo das vidas.

A palavra "risco" transformada em categoria conceitual-instrumentalburocrática se transversaliza entre os discursos e práticas assistenciais. Encarnam-se nos técnicos e materializam-se nos seus saberes e atividades: enquadram, inclusive, as formas com que se deve escutar as famílias acompanhadas, tornando-se uma espécie de intérpretes e, portanto, construtores de uma realidade.

Em uma experiência vivenciada em um grupo realizado com psicólogos e pedagogos de um serviço especializado do SUAS, uma das profissionais com mais experiência nos diversos dispositivos da política de Assistência Social do município relatou a considerável diferença entre os discursos dos usuários, a depender de qual dispositivo o profissional representa. Em sua concepção, nos CRAS os profissionais têm mais acesso a informações sobre as famílias e como elas vivem, pois entre os usuários da política existe a concepção de que quanto mais mazelas relatarem nos atendimentos realizados pelos técnicos do equipamento mais acesso a benefícios terão. Em contraposição, nos CREAS, os relatos das famílias dão-se de maneira a omitir a realidade vivida. Isso aconteceria, pois os CREAS, diferentemente dos CRAS, têm uma relação mais estreita com o sistema de garantia de direitos e, nesse sentido, o controle estatal incidiria mais diretamente sobre as famílias atendidas pelos serviços especializados.

Tal relato indica elementos do que entendemos por uma "escuta diagnóstica". Ocorrendo a partir de categorias prévias ao encontro/atendimento, à medida em que os usuários dos CRAS relatam sua história, vida cotidiana e, sobretudo, as 
vulnerabilidades/riscos que os atravessam, os técnicos operadores da política não só interpretam o que foi dito mas traduzem essa narrativa em termos de benefícios e encaminhamentos possíveis. A partir de um determinado discurso obtém-se respostas às demandas que, embora sejam singulares em cada história, trazem uma certa regularidade e, nesse sentido, são estabelecidos limites nas práticas discursivas tanto dos usuários quanto dos técnicos da política.

São nesses limites discursivos da PNAS que a escuta qualificada operar-se-á através de um constante processo de tradução das narrativas escutadas nas terminologias delineadas nos documentos. É comum encontrarmos entre os técnicos operadores dessa política discursos que beiram o clichê para descrever suas práticas: "garantir direitos", "possibilitar o acesso às outras políticas", "exercer proteção social em situações de vulnerabilidade", "fazer acolhimento", "oferecer escuta qualificada", entre outros. Ainda que cotidianamente os profissionais coloquem seus saberes na direção de operacionalizar - trabalho acima nomeado, o caráter generalista presente nos discursos não demonstra quais são as mobilizações prático-afetivas que possibilitam que o trabalho prescrito seja efetivamente realizado no cotidiano. Essa mesma posição também pode ser observada na maneira como os documentos prescrevem o trabalho.

Pensar a PNAS na esfera instituída como uma gramática, um esquema de pensamento materializado em diversos dispositivos, requer reconhecer certa rigidez que se configura por uma série finita e delineada de regras. Assim, conforme afirma Larrosa (2014, p. 37), "...qualquer coisa que se produza em seu interior dá-se a impressão de 'já dito', 'já pensado', uma sensação de que pisamos num terreno conhecido, de que podemos continuar falando ou pensando em seu interior sem dificuldades, sem sobressaltos, sem surpresa".

Deve-se considerar que a produção maciça de documentos e linguagens específicas para o trabalho em questão favoreceram a maneira como a política se desenha e se assenta sobre os pilares da seguridade social, rompendo com práticas assistencialistas anteriores. Dessa forma, o estabelecimento de uma gramática sobre as condições do Trabalho Social com Famílias enfrenta um paradoxo fundamental: na medida em que visa romper com as práticas de controle anteriores, implantam-se novas modalidades de controle sob - crivo de conceitos como "justiça social", "equidade", "vulnerabilidade" e "riscos sociais" (Almeida, 2016). Nesse sentido, criar ou não uma linguagem para que se fale sobre o outro traz, inevitavelmente, implicações políticas.

À medida em que aquilo que é escutado delimita as práticas de controle, o crivo da escuta técnica e a eliminação ou manutenção em segundo plano de outras possibilidades de sentido podem ser utilizadas em prol do exercício de violência contra o usuário. Nesse sentido, faz-se necessário pensar sobre a problemática do processo 
de tradução. A tradução comporta diferentes sentidos e perspectivas. Pode se referir tanto ao produto final, tal qual um texto traduzido, como ao ofício do sujeito que desempenha diversas tarefas no ato de traduzir. A tradução tem papel central na discussão que aqui pretendemos discorrer, qual seja, a questão da equivalência.

Algumas perspectivas teóricas como as que derivam de Jakobson partem da premissa de que a equivalência interlingual faz-se possível uma vez que a tradução é empreendida não pelas unidades de código (palavra por palavra) mas sim pela mensagem que toda uma sentença transmite. Por admitir que não há equivalência completa entre as unidades de código, dois códigos distintos podem ser equivalentes através da mensagem, isto é, do significado que comportam (Scherer \& Kader, 2012). Assim, a noção de equivalência visa atender à diferença como atividade tangível e também a finalidade a ser realizada enquanto uma das tarefas basais da linguística enquanto disciplina.

No que tange ao atravessamento com a escuta, é pelo viés da diferença, ou seja, pela impossibilidade fundamental de equivalência, que abordaremos a questão da tradução enquanto ofício do trabalhador do SUAS. A escolha do referencial em questão comporta implicações ético-políticas que buscam colocar em causa os processos de dominação presentes na atividade de traduzir.

A escolha pela perspectiva da diferença foi feita porque, historicamente, os saberes psicológicos se mantiveram distantes das populações e dos cenários que caracterizam a referida política pública (o que é indicado, por exemplo, em trabalhos como os de Dimenstein, 1998; Bock, 2009). Hüning et al. (2018, p.58) articulam esse distanciamento com a questão da linguagem ao afirmar que:

Grande parte do distanciamento entre os mundos da psicologia e da política de assistência social, e das dificuldades diante dos cenários que se apresentam, decorre da limitação de uma interlocução em termos da experiência que possa ser comunicada por outras linguagens (grifo nosso).

Observa-se que estas linguagens, assim como outros saberes provenientes da modernidade e herdeiras de modelos científicos, visam a objetividade, controle e a universalidade da experiência (Larrosa, 2014). Contudo, conforme adentram a PNAS, os psicólogos deparam-se concomitantemente com a insuficiência teórica, técnica e operativa, ou seja, a ausência de elementos simbólicos a partir dos quais possam atuar.

Os saberes produzidos pela Psicologia, tradicionalmente, caracterizam-se como instrumento político-ideológico liberal que contribui para a manutenção das estruturas de dominação, na medida em que naturalizam o fenômeno psicológico enquanto universal. 
Nesse sentido, há um modelo hegemônico amplamente disseminado no campo social e reiterado pela Psicologia. Segundo Dimenstein (2000, p. 97), "existe, portanto, a ideia de um indivíduo autônomo, senhor de si e independente, ou seja, ausente de vínculos e dos determinismos universalmente definidos pela cultura, que marca a ideologia ocidental moderna".

Enquanto discurso que se transversaliza os dispositivos da política, os próprios cadernos e orientações técnicas sobre o trabalho do psicólogo nesse contexto convocam a categoria a pensar novas formas de produzir conhecimento e de intervir na realidade social caracterizadas pelo abandono de paradigmas que tenham em seus pressupostos a perspectiva do controle em detrimento de um trabalho necessariamente relacional e, por isso mesmo, não tangível:

Dentre as características do trabalho em serviço destaca-se o fato de que existe uma simultaneidade entre a produção e o consumo do serviço e de que ele não é gerador de um produto que possa ser armazenado. Tal característica faz com que o trabalho em serviços também se caracterize pela intangibilidade, embora possa conter elementos tangíveis no processo de trabalho. Isso remete a outra característica do trabalho em serviços que é a sua natureza relacional, pois implica o estabelecimento de uma relação entre o prestador e o usuário do serviço. As características do trabalho em serviço impedem que ele seja totalmente controlado ou capturado e, portanto, a sua qualidade e direção dependem também da relação que se estabelece entre o prestador e o usuário do serviço (Brasil, 2016, p. 16-17, grifos do autor).

Diferentemente dos atendimentos e acompanhamentos sistemáticos presentes no espaço das clínicas particulares, a natureza do trabalho encontrado pelos profissionais na Assistência Social muda radicalmente, da forma como os atendimentos são divididos cotidianamente entre as diversas famílias até as demandas e narrativas que são escutadas. Embora a Psicologia possa ser entendida como uma disciplina que tenha se mantido estrangeira a esse campo, entendemos que ela pode contribuir com os saberes que comportam suas teorias.

A Psicologia, ou melhor, as psicologias, devem encontrar seu compromisso social, pois o eu não se constitui sem o outro, ou seja, não há individualismo que se sustente na ausência do social. Se o paradigma moderno é o da consciência que propicia o individualismo, o paradigma contemporâneo é 0 da linguagem que pressupõe 0 encontro intersubjetivo. 0 "paradigma da linguagem" apenas demarca o campo das 
teorias que concebem o sujeito originariamente como "ser social", "ser-no-mundo", "ser comunicacional", "ser-com", enfim, mergulhado no universo das interações simbólicas (Moreira, Romagnoli, \& Neves, 2007, p. 616).

Ainda segundo as autoras, é dentro dessa perspectiva inter-relacional que a clínica se expressa como plano de produção coletiva e sustentação da alteridade. A tradução aqui é tomada como elemento em constante funcionamento e articulador de subjetividades, numa tentativa contínua de produção de sentidos compartilhados.

Nessa direção, Freitas (2014, p. 165) aborda a tradução enquanto atividade cultural e discursiva em um confronto com a alteridade, evidenciando a impossibilidade de uma relação amorosa entre duas personagens, na medida em que há uma tentativa de perpetrar domínio sobre um dos polos (o colonizado) utilizando como instrumento a imposição de uma linguagem. Assim, no processo de colonização, busca-se "[...] nomear todas as coisas a fim de possuílas, transformando o estranho em familiar, o desconhecido e ameaçador em algo conhecido, procurando, assim, dominar e controlar aquilo que Ihes causava medo, desconforto ou estranheza".

Pensar a tradução enquanto equivalência de sentido passível de ser atingida suprime a prática em questão enquanto campo em que opera a negociação de sentido e, portanto, exercício político, já que "[...] os signos entram em circulação, constituem um discurso, constroem significados que se disseminam e entrecruzam e são, ao mesmo tempo, produto e produtores de ideologia" (Rodrigues, 2000, p. 97). Desse modo, onde opera-se a linguagem há necessariamente exercício de poder.

Nesse sentido, a problemática a que pretendemos dar visibilidade são as relações de poder existentes no ofício de traduzir e, especificamente no contexto da Assistência Social, indagando sobre quais as implicações das práticas de tradução que adotam a questão da equivalência como passível de ser atingida, especialmente naquilo que se escuta nas narrativas das famílias, traduzidas e interpretadas de acordo com as terminologias presentes nos documentos, que irão direcionar respostas por parte dos profissionais técnicos para as demandas que se apresentam. Especificamente no contexto da política de Assistência Social, na sua linguagem configurada enquanto dispositivo-controle, quais as maneiras com que se traduz a vida de seus narradores-usuários? Como a tradução pode dar-se em prol do exercício de violência e subalternação?

Gama (2017) relata um acontecimento ocorrido em 2011, quando, durante o período de chuvas enfrentado anualmente pela cidade de 
Aracaju, os profissionais adentravam as casas evocando as experiências anteriores já passadas pelas famílias, que envolviam desde a segurança dos pertences pessoais, privacidade e a garantia de não terem as casas demolidas durante o remanejamento da população daquela comunidade. Experiências passadas que tornavam o empreendimento de convencimento das famílias a aderirem à "solução" dada pela gestão municipal uma tarefa quase impossível:

Entre a fácil divisão entre orgulhosos e envergonhados profissionais, a chuva caía sobre todos e estratégias se teciam nas ressonâncias do acontecimento que tensionava e diluía a ação municipal. Sem proteção ou disciplina suficiente que os garantisse, alguns (des)envergonhados termos de responsabilidade eram submetidos à materialidade da chuva. $O$ termo, mesmo quando assinado, na pouca porosidade de uma estratégia manca não sobrevivia aos pingos d'água travestidos em "desatenção" de alguns profissionais. Desmanchados na água, os papéis se tornavam farelos borrados de tinta nos fazeres de profissionais atentos menos para as informações e muito mais para a experiência que ali se esboçava. Experiência que versava sobre uma força que, como toda força que se afirma impiedosa, vaza o conceito de vulnerável (Gama, 2017, p. 22-23).

Diante da tarefa dilemática, para alguns profissionais a exposição dos termos à chuva pode ser entendida como uma conduta técnica que faz resistência a uma das múltiplas ambiguidades que atravessam os cotidianos desses trabalhadores, encarregados fundamentalmente pela gerência de vidas periféricas, que também resistem à adequação e às violências impostas por um Estado que é conivente e não combativo às desigualdades sociais.

O exercício de tradução descrito nessa seção através dos documentos e saberes disciplinares das áreas de conhecimento (científico) que compõem a PNAS nomeia aqueles "outros" que não estão nos nossos sistemas de necessidades, passando a incluí-los nesse mesmo sistema que prevê, dentre outros ordenamentos, a inserção no mercado de trabalho formal (sem mencionar as mazelas desse sistema) e o exercício do cuidado feito pelas famílias (cuidado esse que comumente materializa-se através da responsabilização apenas das mulheres). Importante ressaltar que estes ordenamentos não estão isentos de uma materialidade histórica e cultural, ainda que esse ponto não seja questionado pelos documentos nem pelos saberes que constituem o campo socioassistencial.

Orientar a atuação apenas nas prescrições acerca de como deveria ser essa outra alteridade pode tornar os serviços socioassistenciais lugares onde se exerce incisivamente a higiene social. Enquanto outra 
posição, é possível observar a produção de outras possibilidades como as apontadas por Gama (2017) e Huning, Cabral e Ribeiro (2018) - capazes de denunciar o campo da Assistência Social como lugar de resistência: das vidas que são atendidas e também dos trabalhadores que operam tal política.

\section{Escutar, diferenciar e criar: trajetos para as práticas de subversão}

Alinhado às (im)possibilidades da Psicologia dentro da política denunciada no trecho indicado anteriormente, uma experiência com um grupo focal constituído por psicólogos e assistentes sociais atuantes no SUAS permitiu identificar o uso da terminologia "escuta" de maneira corriqueira entre os psicólogos, como também apreender alguns sentidos compartilhados entre os profissionais acerca dessa palavra. Era comum, por exemplo, os participantes relatarem a escuta como o último recurso a ser ofertado diante das contradições, impossibilidades e violências ocasionadas dentro da própria política: "Às vezes a única coisa que temos a ofertar é a nossa escuta".

Mas sobre o que tal escuta opera? Silva e Dias (2018, p.15) afirmam que se trata do processo de "[...] construção de corpos dóceis, passíveis de transformação e aperfeiçoamento para adoção de determinadas práticas e modos de conduta [...]". Nesse sentido, considera-se que as ações empreendidas na Assistência Social tratam de um trabalho que se pauta necessariamente em uma ética voltada para o ajustamento, disciplinamento, e formulação de modos de vida que vinculam os corpos a um modelo demarcado previamente ao qual, a partir do trabalho social, as populações devem estar alinhadas.

A partir da identificação de que entre os próprios dispositivos da política operam situações geradoras de violência que incidem diretamente nos usuários, foi observado que, especialmente na descrição dessas incidências, surge nos discursos dos profissionais outra forma de escuta, fortemente articulada aos limites impostos no e pelo trabalho. A partir dessa condição de impotência, entendemos que tal escuta pode ser potencialmente criativa ao assumir que as respostas dadas pelos especialismos disciplinares e pela própria política mostram-se insuficientes ou mesmo violentas, denunciando a necessidade de se criar outras formas em seu saber-fazer. Para isso, as práticas precisam ultrapassar a égide do poder disciplinar, alinhadas a uma lógica de linguagem descrita pelo conceito de exame que, em última instância, visa minimizar e direcionar as múltiplas formas de viver ao aumento de seus efeitos utilizáveis (Foucault, 1987), visando responder às demandas de um contexto social movimentado pela lógica do capital. 
Consideramos, porém, que é pela via da construção de outra direção ético-política que fundamentar-se-á a criação de formas de trabalho que façam resistência às práticas de ajustamento. Para tanto, é necessário que haja algum nível de subversão que, no nível da linguagem, dar-se-ia nos seus limites. Ou seja, uma linguagem que se pretende ética mostra o seu próprio fracasso constitutivo e não aquilo que as coisas são, os fatos. Ao valorizar que o mundo é da ordem do inexpressável, como afirma Mèlich (2001, p. 276), "A ética, porém, não diz o que é, a ética valoriza o mundo, julga-o".

Pensando no contexto SUAS, as práticas que se limitam puramente a descrever a realidade (parte fundamental das práticas de exame), acabam por delimitar ou mesmo restringir as possibilidades de um diferenciar, as possibilidades de nascimento provenientes da contingência e da finitude:

... A palavra humana é uma palavra múltipla, é a palavra que pode ser dita de outro modo, a palavra que acolhe e deseja, a palavra que recebe e que dá. A palavra múltipla, a palavra (po)ética, é a palavra que nos ensina que existe no mundo a capacidade de inovar, de inventar, de não ficar preso pelo dito, pelo dado, pelo destino. Em toda vida humana tem lugar uma tensão antropológica fundamental, a tensão entre a contingência e a novidade: a finitude. (Mèlich, 2001, p. 279).

Em detrimento da escuta diagnóstica, as práticas que resistem à disciplina não passam pelos processos de tradução descritos na sessão anterior, ao menos não nos crivos impostos pelos jogos de verdade disciplinadores da ciência em que na produção de conhecimento não há uma adequação ao objeto numa relação de assimilação, mas sim uma relação de distância e dominação (Foucault, 2003). Nesse sentido, é necessário que se desaprenda. Entendemos por desaprender o processo de deixar que a realidade que se experimenta modifique o que acreditávamos conhecer, exercício contrário aos discursos especialistas que enquadram 0 vivido às teorias. Nesse sentido, os referenciais teóricos deixam de ser um anteparo que antecipa, interrompe e mata a experiência. Sobre esse ponto, Larrosa (2014) pontua:

E digo a ela que talvez seja essa a lição dos poetas: que não se trata de falar sobre a infância, mas sim de contar, de colocar em palavras, a experiência de um encontro, ou um reencontro, com a infância. E que, quando esse reencontro tem a forma do pensamento, ou seja, quando o encontro com a infância nos faz pensar e traduzirmos esse pensamento em palavras, então talvez o que fazemos é filosofia, ainda que não saibamos disso (Larrosa, 2014, p. 152). 
Nessa passagem, o que o autor coloca é necessariamente um reencontro com as teorias na sua potência enunciativa multiplicadora das linguagens que já existem. Assim, a tradução que estabelece o crivo dessa escuta não comporta a noção de que a experiência é traduzível em terminologias capazes de representar a realidade, mas sim a tradução enquanto exercício de diferenciação, produz variação da e na realidade experiencial. Desse modo,

... se trata de manter sempre na experiência esse princípio de receptividade, de abertura, de disponibilidade, esse princípio de paixão, que é o que faz com que, na experiência, o que se descobre é a própria fragilidade, a própria vulnerabilidade, a própria ignorância, a própria impotência, o que receptivamente escapa ao nosso saber, ao nosso poder e à nossa vontade" (Larrosa, 2014, p. 42).

Nas modalidades (po)éticas de escutar, conversar, escrever e aprender também existem os processos de tradução e interpretação. Porém, estes irão se dar de maneira não fixada a uma tradição ou um método, mas no exercício contínuo de traduzir e interpretar, "no jogo, no conflito das interpretações, na contradição. Pois nunca se está de todo em uma interpretação, sempre se vive no conflito" (Mèlich, 2001, p.280). Assim, o encontro com o outro - muitas vezes, identificado pelo o usuário, mas não subscrito a ele - é marcado pelo imprevisível, fomentando a criação conjunta dos códigos que servirão de base para a própria relação.

Nesse sentido, pensar uma outra ética para o campo da Assistência Social faz com que a atuação do técnico operador dessa política ressoe juntamente com a palavra descontinuidade, isto é, no conflito que gera intervalo para o porvir. Atuação que se distancia das determinações do passado do usuário e da fabricação de um futuro utilizável para este. A nível de linguagem, tal atuação constrói intervalos: transmite a palavra enquanto movimento de desapropriação de si para "dar sua possibilidade de dizer outra coisa diferente daquilo que já dizem. Dar a palavra é dar a alteridade constitutiva da palavra" (Larrosa, 2001, p. 291) no seu exercício sumário de diferenciação.

Na outra via, a referente ao trabalhador, vê-se uma distância das determinações dos documentos e do saber disciplinar. Assim, tais práticas não se esgotam nas ações prescritas e previstas nos documentos oficiais ou mesmo na adequação dos usuários às categorias indicadas pelos constructos teóricos. Nesse sentido, o trabalho provoca práticas de subversão dos documentos, da chefia, da gestão, da rotina institucional, do saber disciplinar e dos poderes que agrega. Tal perspectiva - que aponta para a multiplicidade - 
ultrapassa a direção de identificação de traços uniformes e homogeneizadores, o que impõe a necessidade de modificação do que se encontrava indicado e que serviam de parametrização às leituras possíveis, pelos técnicos dos aparelhos da política, dos usuários.

\section{Considerações finais}

Considerando que o trabalho executado dentro PNAS deve estar alinhado às suas proposições teóricas, técnicas e políticas presentes nos documentos, o que será escutado passará pela tradução a partir da seleção dos saberes que fundamentam os discursos profissionais e também dos conceitos norteadores dos cadernos que disciplinam e direcionam a escuta desse trabalhador. Isso significa que as narrativas escutadas nesse contexto passam, no mínimo, por dois crivos: o das linguagens da política e $p$ das linguagens dos saberes disciplinares, dentre eles, o saber da Psicologia.

O arcabouço conceitual dos documentos permite a obtenção e constituição dos saberes, construídos a partir do direcionamento da escuta para o que "interessa" ao campo da Assistência Social, em um jogo de perguntas que produzem jogos de verdade. Dessa maneira, quanto mais ritualizado o processo de exame dentro dos dispositivos de disciplina, no contexto da política pública representados principalmente pelo preenchimento/atualização dos cadastros e relatórios bem como as visitas domiciliares, o trabalho estará também mais alinhado ao controle disciplinar da escuta diagnóstica. Visto que os conceitos encontrados nos documentos da política se alinham pelo que se entende pelo regime social-liberal, em última instância, o poder disciplinar de vigilância-punição, que se utiliza da escuta diagnóstica das famílias, visa a produção de subjetividades também em consonância com a lógica capitalista.

Nesse sentido, não podemos entender a Política Nacional de Assistência Social como um campo à parte da conjuntura pela qual passa o nosso país, sendo também atravessada por uma concepção neoliberal que coloca em marcha o enfraquecimento do Estado no que tange à responsabilidade com políticas sociais. Somado a isso, pode-se correr o risco das ações e instrumentais da política (como a própria escuta) serem tomados como meios de captura da subjetividade em prol de um modelo de sujeito e sociedade que coloca em marcha e naturaliza uma visão estigmatizante, discriminatória e que reitera as desigualdades social.

A delimitação dentro do campo da Assistência Social de uma perspectiva ético-política inclusiva e crítica se mostrou como necessária para criação de outras práticas que possam levar a formas de escutar que excedam o caráter de vigilância/adequação presentes 
na escuta diagnóstica. O profissional que ocupar o lugar de operador da referida política pública confrontar-se-á com a iminente ambiguidade de ser um instrumento de reprodução social ao mesmo passo em que cria espaços de subversão, isto é, intervalos dentro da reprodução, ou ainda, diferenciações em meio a um universo de repetições. E aqui, mais uma vez, a noção de descontinuidade nos auxilia a problematizar os processos previstos que atravessam 0 cotidiano dos serviços socioassistenciais de forma a ampliar a visão existente e construir alternativas à visão que preconiza a dimensão individual que atravessa a lógica neoliberal.

A (po)ética de escutar se aproximando da descontinuidade requer que se abandone paradigmas de trabalho que visam o controle sobre a alteridade e diferença representados pelas práticas de exame. Escuta que se aproxima dos limites da linguagem, naquilo que as palavras falham para expressar, em suma, uma escuta que se atenta à valorização do mundo. As incidências dessa escuta direcionando-a justamente a suas fronteiras, reconhece nas impotências constitutivas do exercício da linguagem a sua própria potência: uma potência de nascer que faz diferenciar.

\section{Referências}

Almeida, S. S. (2016). Análise dos conceitos sociais-liberais de justiça social, equidade, vulnerabilidade social e risco social e suas implicações para a assistência social brasileira (Monografia de Graduação em Serviço Social). Universidade Estadual da Paraíba, Centro de Ciências Sociais Aplicadas, Campina Grande, Paraíba, Brasil.

Barros, M. (2016). O livro das ignorãças. Rio de Janeiro: Alfaguara.

Bock, A. M. B. (2009). Psicologia e sua ideologia: 40 anos de compromisso com as elites. In A. M. B. Bock (Org.), Psicologia e o compromisso social (pp. 15-28). São Paulo, SP: Cortez.

Brasil. Ministério do Desenvolvimento Social e Combate à Fome. (2005). Política Nacional de Assistência Social- PNAS/2004 e Norma Operacional Básica - NOB/ SUAS. Brasília, DF.

Brasil. Ministério do Desenvolvimento Social e Combate à Fome. (2012a). Norma Operacional Básica de Recursos Humanos do SUAS - NOB-RH/SUAS. Brasília, DF.

Brasil. Ministério do Desenvolvimento Social e Combate à Fome. (2012b). Orientações técnicas do PAIF: o Serviço de Proteção e Atendimento Integral à Família - PAIF. Brasília, DF.

Brasil. Ministério do Desenvolvimento Social e Combate à Fome. (2016). Fundamentos ético-políticos e rumos teóricometodológicos para o fortalecimento do Trabalho Social com Famílias na Política Nacional de Assistência Social. Brasília, DF. 
Caliman, L. V., \& Tavares, G. M. (2013). O biopoder e os cães nas sociedades contemporâneas. Psicologia: Ciência e Profissão, 33(4), 934-945. doi:10.1590/S1414-98932013000400012

Cordeiro, M. P. (2018). A psicologia no SUAS: Uma revisão de literatura. Arquivos brasileiros de psicologia, 70(3), 166-183. Recuperado de http://pepsic.bvsalud.org/scielo.php?script=sci_arttext\&pid=S1 809-52672018000300012

Dimenstein, M. D. B. (1998). O psicólogo nas Unidades Básicas de Saúde: Desafios para a formação e atuação profissionais. Estudos de Psicologia (Natal), 3(1), 53-81. doi:10.1590/S1413294X1998000100004

Dimenstein, M. D. B. (2000). A cultura profissional do psicólogo e o ideário individualista: Implicações para a prática no campo da assistência pública à saúde. Estudos de Psicologia (Natal), 5(1), 95-121. doi:10.1590/S1413-294X2000000100006

Freitas, V. (2014). Tradução e diferença: O mais além da linguagem em 'Vasto mar de sargaços' de Jean Rhys. Cadernos De Letras Da UFF, 24(48). doi:10.22409/cadletrasuff.2014n48a129

Foucault, M. (1987). Vigiar e punir: Nascimento da prisão. Petrópolis: Vozes.

Foucault, M. (2003). A verdade e as formas jurídicas. Rio de Janeiro: NAU.

Gama, B. C. (2017). Insistências entre o vulnerável e o vencedor no governo do vivo: Ensaios na Política Pública de Assistência Social (Tese de Doutorado em Psicologia). Universidade Federal Fluminense, Niterói, RJ, Brasil.

Hüning, S., Cabral, R., \& Ribeiro, M. (2018). Nas Margens: Psicologia, Política de Assistência Social e Territorialidades. Polis e Psique, 8(3), 52-69. doi:10.22456/2238-152X.86108

Larrosa, J. (2001). Dar a palavra: Notas para uma dialógica da transmissão. In J. Larrosa \& C. Skiliar (Orgs.), Habitantes de Babel, políticas e poéticas da diferença. Belo Horizonte: Autêntica.

Larrosa, J. (2014). Tremores: Escritos sobre experiência. Belo Horizonte: Autêntica.

Maciel Jr, A. (2014). Resistência e prática de si em Foucault. Trivium - Estudos Interdisciplinares, 6(1), 1-8. Recuperado de http://pepsic.bvsalud.org/scielo.php?script=sci_arttext\&pid=S2 176-48912014000100002\&lng=pt\&tIng=pt

Mèlich, J. C. (2001). A Palavra Múltipla: Por uma Educação Poética. In J. Larrosa \& C. Skliar (Orgs.), Habitantes de Babel, políticas e poéticas da diferença. Belo Horizonte: Autêntica.

Moreira, J. O., Romagnoli, R. C., \& Neves, E. O. (2007). O surgimento da clínica psicológica: Da prática curativa aos dispositivos de 
promoção da saúde. Psicologia: Ciência e Profissão, 27(4), 608621. doi:10.1590/S1414-98932007000400004

Rodrigues, C. C. (2000). Tradução: A questão da equivalência. Alfa: Revista de lingüística, 44 (n.esp.), 89-98. Recuperado de https://periodicos.fclar.unesp.br/alfa/article/view/4281/3870

Scherer, A. E., \& Kader, C. C. C. (2012). Os aspectos linguísticos da tradução à luz dos pressupostos teóricos de Roman Jakobson versus a vertente da tradução da linguística de corpus. Entretextos, 12(1), 132-148. Recuperado de http://www.uel.br/revistas/uel/index.php/entretextos/article/vi ewFile/8952/11600

Silva, R. B., \& Dias, D. M. T. (2018). Da disciplina ao controle: Breve análise das formas de dominação do trabalho na contemporaneidade. Revista Espaço Acadêmico, 18(209), 1222. Recuperado de http://periodicos.uem.br/ojs/index.php/EspacoAcademico/articl e/view/44681

\section{Endereço para correspondência \\ Natália Sanches}

Av. São Paulo, 926, Centro, CEP 86010-060, Londrina - PR, Brasil

Endereço eletrônico: ntsanches9@gmail.com

\section{Rafael Bianchi Silva}

Rua Felício Marconi, 201, Condomínio Vale do Arvoredo, CEP 86047-595, Londrina PR, Brasil

Endereço eletrônico: tibx211@yahoo.com.br

Recebido em: 07/09/2018

Reformulado em: 27/10/2019

Aceito em: $27 / 10 / 2019$

\section{Notas}

* Graduanda em psicologia pela Universidade Estadual de Londrina. Bolsista de Iniciação Científica CNPq/PROIC-UEL (2018-2019).

** Pós-doutorado em Psicologia (UEM); doutor em Educação (Unesp/Marília), docente do departamento de Psicologia Social e Institucional e do Programa de Pós-Graduação em Psicologia na Universidade Estadual de Londrina (UEL).

Financiamento: CNPq.

Este artigo de revista Estudos e Pesquisas em Psicologia é licenciado sob uma Licença Creative Commons Atribuição-Não Comercial 3.0 Não Adaptada. 